\title{
Cookies for Peace and a Pedagogy of Corporeal Generosity
}

\author{
Stephanie Springgay
}

\section{INTRODUCTION}

Contemporary artist Sophie Calle has a fascination with the strange(r), revealing and embracing the uncanny-of-the-everyday. For example she hired a detective to follow her and document her movements, found a lost address book and then wrote to everyone listed in the book asking them to describe the person the book belonged to, worked as a chambermaid in order to document the personal belongings of guests in each room, inhabited the life of a character from a novel, and hosted a birthday party for herself each year where guests were required to bring gifts that would be documented and preserved in curiosity cabinets. Her methods include meticulous documentation, observation, and surveillance - mundane gestures that explore the moments of sociability and art of the everyday. ${ }^{1}$

Sophie Calle's interventions create possible moments of interaction, whether inviting people to attend a birthday celebration or inhabiting a phone booth in a large city. They are rituals of the instant, the moment, and the mundane. By altering the moment, making the encounter susceptible to modification, and putting things to strange new uses, Calle gestures at meanings that are not named, but that are present.

Nicolas Bourriaud (2001) maintains that the role of contemporary artworks "is no longer to form imaginary and utopian realities, but to actually be ways of living and models of action within the existing real" (p. 13). Art becomes a moment to be lived 
through, opening unlimited conversations. Bourriaud (2002) suggests a difference between traditional gallery exhibitions and contemporary art that is relational. Traditional viewing apparatuses establish a universal audience. The artwork would always (save for gallery closures and the like) be available to the public in an unending time display. Furthermore this unlimited access to the work of art produces, in Bourriaud's understanding, an audience of the same. In other words the artwork becomes permanent and monumentalized. Today many contemporary artworks are not only temporal they invoke attention of a different nature - audiences who are summoned by the artist for a limited duration and with a specific role in mind. Artwork that takes as its nexus a social interstice, where the art is formed in relations between people and the social context of these interactions, is what art critic Nicholas Bourriaud terms relational aesthetics. In the context of education, how might students engage with relational aesthetics? And if relationality implies social encounters, what might a pedagogy of corporeal generosity look like?

This article examines visual culture created by secondary students as part of a larger research study that investigates how youth understand and mediate body knowledge. During a six-month period students created a number of visual artworks, using a diversity of material explorations as a means to think through the body as a process of exchange and as a bodied encounter. Here, I explore two student artworks - a mail art piece and an intervention-based performance work - through the perspective of relational aesthetics. Explorations attend to the nature of the gift and the practice of giving, examining the ways in which bodies and knowledges are produced through such 
encounters. Pedagogical implications will reconsider what it means to give and create meaning that is relational and corporeal. Corporeal pedagogy, I argue, becomes directive and performative in that it is not merely about deconstructing texts but about situating politics itself within a broader set of relations that addresses what it might mean to create modes of individual and social agency that enable rather than shut down democratic values, practices, and forms of sociality. (Giroux 2005, 7).

Pedagogy then becomes a means of imag(e)ining new forms of civic engagement constituted with, in, and through the body.

Using the arts-based methodology, a/r/tography, ${ }^{2}$ students created performance, installation, and new media art as a means of inquiring into the lived experiences of their bodies, while also exploring the relationship of the body to visual culture. While there is limited space to develop arguments for the use of arts based methodologies, what is important for the "reading" of this article, is an understanding that the students works of art and their conversations make up the research "data" and as such the artwork needs to be recognized on its own (not simply as described through student "words") exemplifying the complexities of student understandings of corporeal generosity. In other words, the works of art created by students are as much constitutive of their understandings as are the transcribed conversations that are presented in this article. Moreover, emphasis in this study was placed on the artwork created by the students and less on the brief and informal interviews conducted with the students - thus "data" are a living visual culture (see Rogoff, 2000). Conversations that students held around their artwork opened up possible ways for them to continue re-creating their creative explorations - to move in new 
directions. Rather than thinking of studio projects that had a beginning and an end (a typical art education curriculum and pedagogical approach), this study understands the arts works themselves as relational - they are constituted in and through bodied encounters.

How does one write about such visual and bodily relational encounters? How does one acknowledge and express the ambiguous potential of the body in - and as visual culture without predictably and immediately containing that potential within the limits of academic writing? How in other words, can one use writing to describe that which surpasses the boundaries of language, and in turn, how can one describe such a situation without falling into an uncritical embrace of the uncertain, the embodied, and the experiential? I attempt to address these questions through performative writing (Pollock 1998) that takes into account the complicated spaces of bodily encounters and visual culture. I play with "linearity" entangling together three "texts" in an attempt to recognize the multiple performances at play in the research study. As the center of my article, the "text" contains my analysis of the students' artwork and follows the formatting of a word-processed document. Threaded throughout the "body of the text" are the students' works of art themselves, which can be found at www.springgay.com under "research" and "inside the visible." Reflecting the structure of an online document, the hypertext of images is not intended to "represent" in visual form what is analyzed in the "body of the text" rather, the art itself needs to stand alone as something else yet unnamed (see Eisner 1997; Bagley and Cancienne 2001; Mullen 2003). In her book Places of Learning Elizabeth Ellsworth (2005) explores the potential for thinking about pedagogy as something "in the making," as an embodied, experiential, and relational 
process. The places she examines, which range from multimedia projections to public events and performance art, present emergent pedagogical qualities in the making. Moreover, she positions them as anomalies, places that are irregular, peculiar, or difficult to classify only when viewed from the "center" of dominant educational discourses. The students artworks and their bodily relational encounters that are the context of this article, need to be considered from this perspective — not as "things" already made into concrete facts, projects to be taught, nor metaphors for teaching and learning, but in the making"harboring and expressing forces and processes of pedagogies as yet unmade, that provoke us to think or imagine new pedagogies in new ways" (Ellsworth 2005, 6).

The third "text" that intersects this article is constructed from student conversations that were either videorecorded or annotated in my visual journal at the time of the research study. Student conversations comprised secondary data, which assisted me months later in recalling memories and sensory experiences of the bodily encounters and events. Intersected with student "images" these conversations allow for intertextual voices to resonate within the text. I have tried to weave the three texts together, to unsettle the split between scholarly analysis, the experiencing body, the visual, and that which cannot be contained within language. All of this is an attempt to think/write/image relationally — to locate the body in the threshold of meaning making and to understand that to be a body is to be continuously in relation with other bodies and the world.

\section{CUPCAKE CRUMBS AND SEEDS: THE "THINGNESS" OF THINGS}

James $^{3}$ decided that he would like to approach the idea of circulation through a mail project that he would send via the post. The initial impetus was to subvert Canada Post 
and to circulate mail without stamps. To do so, he discovered that if he put the "To" address in the space for the "Return" address and did not affix a stamp to the envelope, Canada Post would return the mail to the "Return" address, which is really the "To" address. While an interesting concept, beyond subverting the postal system, the small gesture terminates once the mail has reached the intended recipient. I asked James if he could think of something to include in these letters that might in fact provoke a response, to start a conversation of sorts. I thought he might actually write about his theories of the Canadian postal system as an institution of power and control and his "no stamp" scheme. Instead he described in a letter his preference for cupcakes based on their superiority over muffins.

When I asked him why he had chosen this topic, his response was, "I was thinking about cupcakes. I just needed some sort of content in the letter to provoke a reaction and I thought cupcakes would do as well as anything. I wanted to express an opinion." I was curious to know if he received the letter in the mail how he might, or if he would, respond. 'I'm not really sure. I'd find it amusing. I'd be happy to get it. If I did respond I'd write something, counter the argument. Or, I don't know if I'd respond just out of laziness but I would have thought about it for sure.”

In addition to the envelopes sent without stamps I provided him with stamps for an additional twenty-five envelopes and suggested he include self-addressed stamped envelopes in order to facilitate ease of response. He used his own home address as the return address, commenting that if he used the school address people would assume it was a school project, which he didn't want. He chose to mail the piece to fifty addresses ${ }^{4}$ 
around the lower mainland, noting that he targeted what he considered to be communities where "alternative thinking individuals lived."

A month passed and no letters had been returned. Somewhat disappointed, James thought that perhaps his letters had not in fact reached anyone, having been lost in the mail. James and Andrew, another student, discussed the fact that James had randomly pulled the addresses out of the phone book; the recipients of his letters were unknown to him and he was unknown to them. Many of the mail art projects use the web to sign-up to receive mail art, thereby bringing the unfamiliar into an already established proximinal relationship. They wondered if James' project perhaps failed to generate a response because the piece of mail was so random and distant it was simply discarded as another piece of junk mail. In fact they realized that because the "To" address was really just an arbitrary address, and the receiver's address was in the "Return" space, many people might read the incorrect "To" address, assume the piece of mail was not for them and had been delivered to the wrong address, and thus forward on the envelope. The possibility of this continued exchange had the two boys quite excited as they dreamt up possible destinations and encounters. You see, James had not used the phone book for the "To" address, so the potential for the "un-real" addresses to become identified as "real" was an unsettling and yet pleasurable concept for Andrew and James.

James added yet another perspective, suggesting that regardless of whether or not people had responded, he was sure his letter had caused people to at least think. As a thinker himself, this was sufficient. However, a few days later James came racing into class, wearing the hugest smile, and exclaimed with delight: "I got mail!" In his hand was 
a small gesture of attention; a gift of communication and exchange. Inside the envelope there was a cupcake wrapper and some crumbs.

Mail art transforms known objects into slightly different configurations or situations. This displacement stimulates thought about how such objects are normally used and our usual forms of behaviour. Dislodging the familiar becomes a means of altering the ways participants become aware of their responsibility in formulating the meaning of events. Mail art sets up situations where artist and audience interrogate the means of social exchange, asking questions about how we interact and the gestures we use. Similarly there is an idea in making work that changes or disappears, whose limits are difficult to identify, complicating patterns of exchange in the process.

On the one hand James' mail art created a situation where recipients of his letters where asked for a brief moment to pay attention to everyday objects - cupcakes and muffins. By extolling the virtue of the cupcake through humorous and poetical means James was not interested in people's opinions of cupcakes and muffins, rather it was intended as an examination of the thingness of things. Thing thingness is not the object itself per se, but its excess, it temporality, and sensuousness. Bill Brown (2001) in theorizing things writes that "thingness amounts to a latency (the not yet formed or the not yet formable) and to an excess (what remains physically or metaphysically irreducible to objects)" (5). Thingness, he suggests, points towards the objects/things' materiality, while naming something else. James' mail art was a reexamination of mundane objects as signifiers for sensory information, knowledge, and memory while highlighting the interwoven nature of our perception and the interplay between art and life. Thingness asks questions not about what things are but about their "subject-object relation in 
particular temporal and spatial contexts" (Brown 2001, 7). Creating artwork that is relational invites thingness to interconnect and intertwine subjects through various bodied encounters.

A number of weeks later, James arrives in class with another response. He had been sent two collage-type text images and a few "cupcake seeds." James has some interesting ideas about the manner in which people have chosen to respond to his work.

The two image-text collages have been created on the inserts for two different Canadian magazines, Canadian Art and Canadian Living. Both magazines are publications that extol the virtues of gentrification and legitimization of what are exemplary art and/or life-style practices. These magazines are part of the corporate economy of exchanges that mark some bodies and objects as being of greater or lesser value and dictate the commodification of visual culture in Canada. However, it is the text on the cards that James is most interested in: "You can have your cake and eat it too," Art/Life/Eat. While one respondent sent back the devoured remnants, the other offered textual interpretations of sensory experiences and provided him with "seeds"-gestations and future possibilities. James says: "Its almost like I sent them an intangible product and they intangibly consumed it, and then they compensated me for it by sending a thing or a notion back. It's like a phantom economy of eating."

Devouring art is a sensual, tactile response-digesting and consuming, not as mastery or control, but in and through the senses, attesting to the body's participation in knowing and meaning making. In their essay on popular culture and pedagogy, Henry Giroux and Roger Simon (see Giroux 2005) suggest that experiences of popular culture are active, communal, and participatory rendering the body meaningful in the production 
of knowledge. Similarly, the “devouring” that was experienced through James' mail art piece reaffirms the place of pleasure and sensuousness in pedagogical actions while “opening up the material and discursive basis of particular ways of producing meaning and representing ourselves, our relations to others, and our relation to our environment so as to consider possibilities not yet realized" (Giroux 2005, 180). Eating is connective; it does not render something meaningless. Eating does not absorb the object of consumption so that it no longer exists; it transforms it, reconstituting materiality in and through the body. Thus, eating takes place in and through time.

The coming of time advenire has as its Latin roots the verb enenire from which "event" is derived. An event is something that is unexpected, a surprise, or an accident. The event, or what Derrida (1992) calls "the gift," dislocates time and ruptures it with an unanticipated future. Such openness allows for embodied experience to be "in the making," to be constituted as unfamiliar, rather than programmed as sequences of events (Ellsworth 2005). It is this event - this giving — that constitutes being in the making that is part of relational aesthetic encounters and embodied in the students' art explorations. Before turning to the second student artwork, in what follows, I briefly examine some theoretical considerations of "the gift" and of "giving" - underlying the unexpected and destabilizing nature of giving and generosity.

\section{THE GIFT AND GIVING}

The enterprise and economy of the gift has been widely theorized by a number of scholars throughout history and in a variety of disciplines. Mauss' classic theory illuminates the nature of circulation and obligation inherent in any concept of the gift. 
Mauss defines a gift as any object or service, including social pleasantries that are given within a web of social interrelationships. According to Mauss a gift involves obligation. A person gives to another person because one is required to act in this way based on imposed systems of exchange that are socially driven. Prestige is bestowed on the recipient with the moral obligation to return. The gift as obligation keeps it in perpetual circulation.

Furthermore, Mauss believes that a gift always embodies traces of the person who gave the gift, suggesting that the gift is always connected to the giver. "One must give back to another person what is really part and parcel of his nature and substance, because to accept something from somebody is to accept some part of his spiritual essence, of his soul” (Mauss 1990, 12). Thus, the gift possesses an animate characteristic of the individual giver and creates a lasting bond between persons. Mauss stresses three aspects of obligation, which are essential to the theory of the gift: to give, to receive, and to reciprocate.

This cycle of giving forms a structure of obligation that constrains both the giver and the recipient. The gift would always be both voluntary and obligatory. Within this bind are two more features of the gift - ownership and certainty. When a gift is given the receiver takes on the ownership of the object in exchange thus possessing something of the giver. The very nature of obligation and reciprocity underlies a certainty that another gift will be given back in return.

In contrast, Bataille (1985) troubles the excessiveness of the gift, arguing that unlike Mauss' theory of a homogeneous gift exchange of static obligation, the very nature of the gift itself implies power, violence, and sacrifice. Bataille arrives at this conclusion 
through an interpretation of the American Native Potlach. Bataille understands a chief's giving as intricately linked to postures of greatness, wealth, and power. This act of giving, Bataille believes was premised on the act of humiliation, where the receiver, who then faced with the challenge of a counter-gift, must return something of greater value. In this gift exchange the giver sacrifices goods that would have increased his wealth, or been used by himself or the community. In the cycle of exchange items given are removed from their participation in the daily lives of those who initially possessed this wealth. For instance, Bataille offers that a chief in trying to outdo another chief would gift food, clothing, and other valuables thereby rendering them useless to his own community. Thus, gifting is premised on surplus and waste.

Obligation that is intertwined with power and excess places the gift within an act of difference, where the surplus of the gift accounts for the giver's prestige. Not only is excess collected and given away, this very act simultaneously destroys and creates surplus. The giver "must waste the excess, but he remains eager to acquire even when he does the opposite, and so he makes waste itself an object of acquisition" (Bataille 1985, 72). A contemporary equivalent might be regifting. For instance, we acquire a number of gifts that we simply do not need or want creating a surplus, which then circulate as an economy in itself.

Excess is what is gained and lost. It reveals something of the sublime, the horror, and terror that inhabits the seemingly innocuous things we do. What is enfolded in the ostensibly mundane activities of the everyday? What meanings are created when we attend to small gestures? What manifests in the interconnections that are imminent in the everyday actions of humans and in our environment? Yet, James' mail art exchange, 
understood through relational aesthetics, reconstitutes excess not as waste or as surplus, but as a fold, ${ }^{6}$ wherein new possibilities and complexities lie. Our participation in relational events (such as the mail art piece) "offers potential ways out of the subject/object and inside/outside binaries by facilitating flows of movement, use, and inhabitation in the spaces between subject and object, inside and outside" (Ellsworth $2005,124)$. It is the potential of the event—gift—as movement that enables different corporealities to be expressed.

Derrida (1992) offers yet another interpretation on the nature of the gift, which according to him is an impossibility. Challenging Mauss, Derrida insists that a gift should not create debt. Obligation marks the gift as not neutral. From this he argues that a pure gift is one that must not come back, must not circulate, and must not be exchanged. There need not be an exchange, no communication, no reciprocal gesture in order for a "gift" to exist. A gift, he argues, is only possible at the instant that it interrupts the circle of exchange. The only way for a gift to become plausible is if the receiver does not recognize it as a gift. Thus, identification and familiarization destroy the gift. According to Derrida, not only can the gift not be recognized as a gift it must necessitate forgetting. Forgetting he argues is not repression of the event, but is an absolute forgetting that absolves. Thus, forgetting and the gift are conditions of each other. This forgetting, argues Derrida, is unknowing. Unknowing is not not-knowing-rather it creates and constitutes the unfamiliar, the peculiar, the uncertain —as "things in the making." Gifts understood in this way are unexpected relational encounters where reciprocity is not informed by obligation but made meaningful because it determines new connections, interstices, and folds. Unexpected gifts cause us to dwell, to pay attention to the thingness 
of things. However, this attention is not a monumental structure; it is fleeting, flickering, moving on, and passing through. Educational theorist, Janet Miller (2005) writes that when we consider things in the making, we are embracing our pedagogical selves as "sites of disunity and conflict, unfinished and incomplete" (229). In the making recognizes “contradictions, gaps, changes and silences in students' and teachers' daily constructions of meaning" (229). When we are presented with "unknowing" and the conditions of being in the making, we are faced with response-ability—or in Levinas' (1969) terms generosity - that is a shift in how we perceive self and other in relation to one another "learning to live together in our differences rather than in spite of them" (Luke 2003, 21). Generosity then shifts from acts of giving constituted in obligation, surplus, or waste, towards an understanding of interaction, a communicative gesture "that does not have as its end anything except its own communicativeness, its own response" (Todd 2003, 48).

As with Derrida's notion of the gift, where there is no expectation of return, no exchange, or circulation of objects, Levinas (1969) insists that the gesture of giving needs to be full. This fullness is not what one gives (my hand is full of something), but the very act of giving and of generosity. It is the fullness of the gesture-its unfamiliarity and unexpected nature that enables bodies to come together, to have a pedagogical encounter, and to produce meaning.

James was initially searching for a returned gift. He was expecting individuals to resend him a response to his letter. Without this reciprocal gesture he felt his project had failed. However, when that first envelope arrived full of cupcake crumbs and a wrapper - the obligatory gesture, itself peculiar and unexpected — caused him to think 
about bodily encounters, the nature of exchange between self and other, in which new meanings are made. Giving in this instance moves from a gesture full of "what," to a gesture that is an opening to the other; an opening that suggests a capacity for relationality not premised on control. This opening is rooted in a response, a receptivity to attend to ambiguity, to admit that we cannot "know" beforehand what it is the Other wants, to be vulnerable to the consequences and effects that our response has on both ourselves and others (Todd 2003). In this sense then, generosity_giving-involves our ability to be altered, to "be in the making," to become someone/thing different that we were before. Encounters, argues Todd (2003), between self and other are a profoundly ethical event premised on unpredictability and nonintentionality. It is ethical when we recognize how the "encounter itself is implicated in the broader relations and circuits of production and exchange" (Ahmed 2000, 152) and thus how different encounters produce different corporealities. It is this understanding of generosity, of being in the making, that I want to further explore in the following section, through an intervention-based artwork, titled "Cookies for Peace."

\section{COOKIES FOR PEACE AND A PEDAGOGY OF CORPOREAL GENEROSITY}

After one particular class discussion Rohan began to formulate an intervention-based artwork that would allow him to participate in the public peace demonstrations. Rohan decided that he would get some of the other students to help him bake peace cookies, which he could hand out in downtown Vancouver where most of the peace demonstrations were taking place. I offered to loan him a digital video camera in case he wanted to document his "intervention.” It seemed interesting enough. I hoped that by 
giving him the camera, the gift of a cookie might be extended into something else. I was curious to see what might erupt. In this section I discuss Rohan's art intervention not in terms of its success as a means of protest but to examine this artwork as a bodily exchange, an act of corporeal generosity. To that extent, I also take up, Ellsworth's (2005) call for a thinking about the "materiality of pedagogy" — a challenge for educators to shift how we make bodies matter in pedagogy.

Rohan returned to school with the camera and a host of stories about his day participating in the peace demonstrations. Trusting him with the camera off-school property for four days had unexpectedly shifted the intervention. Rohan and his coconspirator, Quin, who was not a student at the school, decided that handing the cookies out on the downtown streets, including West Hastings, Thurlow, and Robson, needed to be pushed a bit further. Armed with their innocent-looking brown wicker basket and frosted pink peace cookies, and fueled with excitement, Rohan and Quin approached the American consulate where they were turned away, gave cookies to two police officers parked outside the consulate, and then entered an office building where a number of large gas corporations have regional offices. They brazenly walked into offices handing out their peace cookies to secretaries, office staff, and company vice presidents videorecording their encounters, and in some instances "words of peace." They also spent time handing out the cookies at the peace camps that were set up at the corners of West Hastings and Thurlow, providing an interesting counternarrative to what happened in the corporate offices.

Watching the tape in class was pivotal for Rohan. He narrated his experiences from the day's events, but the video footage provided him with space to reflect on aspects 
that he had not noticed before. In the video we notice that Rohan and Quin did not ask people questions about the global war on Iraq or Canada's involvement in the war, which immediately establishes a context of "for" or "against," a conversational move that is closed rather than open. "Seeing as we were handing out peace cookies we thought we'd just get people to comment on peace. We were really interested in people's understandings of peace. Everyone has different ideas of what peace is, for some peace is the war. We also just thought it would be funny to be in a corporate gas company talking about peace. The irony itself provides a nice critique." Weeks later, Rohan writes in his journal: "What originally began as a project about corporate and public hypocrisy was replaced by a focus on peace. Peace became the replacement message. Ironically, no one disputes the concept of peace."

In class we began to talk about different points in the video. When Rohan and Quin first approached an individual and offered them a cookie most people shook their heads and said no. Watching the video, Rohan noticed something he had not been aware of during the intervention. Although most people were pleasant when refusing the cookies, many of them appeared suspicious of the cookies. Rohan and a few other students began to talk about a "culture of fear" that was permeating the city of Vancouver and Canada more generally. Yet, Rohan went even further in his reflections, moving beyond a critique of the climate of fear tied to terrorism and the un/known (this was also a time in Canada when there was the initial outbreak of SARS, ${ }^{7}$ airports had increased security, and fear of contamination from the unknown "other" was on the rise). Rohan thought that on one level he could understand how people might be wary of a stranger handing out food, given the national media coverage on SARS, but on another level he 
started to think about how his random acts of kindness were in fact producing the unsettling and uneasy tensions. "People look like they are just uncertain about what I am doing. They can't figure out why someone would want to give peace away. They don't seem to understand that I'm not selling things or asking for money. I guess it's also a bit weird that I have a video camera. But mostly I think it's because they are being asked about their opinions and given a peace cookie."

Images, texts, media reports, and the like circulate in the public imagination as a series of pathos ridden or corrupt power struggles, all in the name of goodness and "peace giving" efforts. These artifacts, which I will simply call images, normalize the concept of peace and cannot be taken up outside of history, politics, or ideology. As Giroux (2005) contends, images

do not record reality as much as to insist that what they capture can only be understood as part of a broader engagement over cultural politics and its intersection with various dynamics of power, all of which inform the conditions for reading [images] as both a pedagogical intervention and a form of cultural production (230).

Peace becomes a static symbol that should mean the same to nations and peoples globally. Images of peace necessitate an oppositional understanding where war and terror are countered, erased, and commodified by peace. Peace becomes something those in the Western First World "give," an abstract concept that avoids the conditions that produce it or that it in turn creates. Rohan's cookies are unsettling because they point to the ridiculousness of giving peace, confronting the impossibility of peace as something that can be given. The uneasiness of the frosty pink cookies lies not only in the horrific 
sweetness of their form, and any repulsion people might have to unwrapped food offered by a stranger, but to the unbelonging of Rohan's gesture in the circulation of images on peace. He calls attention to the very thing both peace activists and nation states involved in the war promised: A gift of peace. Yet, his gesture is unexpected challenging us to examine the impossibility and the unknowingness of a gift of peace.

The gesture of giving away peace cookies destabilizes the romanticism and nostalgia for peace, a longing for an unnamed possibility that is so often imaged in the public imagination. His gift forces us to think about peace as belonging to actual existence, its relationality rather than its abstract universal qualities. As a gift that inferred no obligation of return, it ruptures the circulation and economy of goodness and peace, with peace itself, provoking us to think about our own actions and participation in the exchange. As Rohan so candidly states: "To be able to bake, consume [Rohan and Quin apparently ate their fair share of the cookies] and to give the cookies to unsolicited people including the police, represented the ultimate freedom.” Romanticized gestures that reduce the idea of peace to expected conditions and an established set of practices refuse to acknowledge the necessity of unexpected possibilities. When we make peace certain and sure, universalizing it in its own tautology, we close ourselves to the chance of a surprise. If we lack the capacity to openness, to welcome the unfamiliar, we refuse the opportunity to examine and question encounters and the nature of being itself.

Another section in the video shows Rohan and Quin in an elevator. They offer a cookie to a woman who joins them there. She does not respond at all, but immediately starts digging in her purse for something. The camera focuses on her activity until it becomes apparent that what she is looking for is money, loose change, an offering, and 
obligatory gesture in return for a cookie. While Mauss's theory of obligation and exchange could be fitting in this instance, Rohan describes a slightly different understanding of this gesture. Rohan says: "I don't think she was paying us for the cookie. I think she was just doing what she thought was necessary. It had nothing to do with the cookies. She didn't take a cookie. She didn't want one. She was giving money, like you do with the Salvation Army people on the street. People often give without any thought to it at all." Rewatching this scene unfold in the classroom Rohan and a few other students sharing in the conversation made connections between this gesture and foreign aid, and even linked the cookie project to another student's email project on forgiveness and guilt (see Springgay 2005). Andrew offers: "Do you think part of it may be that people have this vision of life and how you should do things for others and in fact life is maybe not that selfless and hard? People in fact do give you things but you're not supposed to get things. Selflessness is really a good thing, pride isn't."

Perhaps education needs to rethink the nature of "the gift" and what it means to give in meaningful ways. Schools often ask students to give. Whether it is to contribute to local food banks, to give time through voluntary/mandatory hours of public service, or to donate time, money, and skills in fundraising efforts for the school, teachers and students rarely think through the nature of giving itself. What we need are curricular and pedagogical interventions that inquire into the exchanges and encounters that produce generosity and the conditions of this bodied production. Education needs to interrogate giving from the perspective of "things in the making"- events that rupture, challenging us to remain open to new possibilities. The possibilities of generosity, the fullness of the 
gesture of giving then, resides not in the "what" is given, but in the corporeal exchanges that take place and the bodies/meanings produced through those actions.

While Derrida's concept of "forgetting" enables giving to generate new possibilities and new assemblages, feminist scholars Sara Ahmed (2000) and Rosalyn Diprose (2002) argue that an understanding of generosity needs to move beyond forgetting, arguing that if the gift only functions if it goes unrecognized then it fails to account for intentionality, materiality, and the corporeality of those involved in an encounter. As such, it is important that when we think of giving — of generosity — within teaching and learning we not do so devoid of embodied experience. Embodied experience, in brief, suggests that we do not have experiences - as in experiences are not separate from our bodied selves_-rather we are experiences (see Merleau-Ponty 1968). Similarly, bodies are not "things" that we "give" meaning to, but that bodies are meaning (Grosz 1994; Nancy 2000). Understanding the body as meaning, as opposed to a container in which we store or put meaning, resists an understanding of pedagogy as something that is enacted by bodies onto bodies. Rather "teaching becomes the activity of participating in the 'becoming pedagogical' of 'expressive materials' distributed across many teachers, sites, events, and interactions" (Ellsworth 2005, 28). In other words, teachers, students, and the sites of learning do not pre-exist pedagogy — they are invented in the process. Thus, we might shift from trying to "know" and then "teach" (generosity) to engaging with it as an event that has not yet ended and to contemporaneously respond to it" (Ellsworth 2005, 19).

Thinking about pedagogy relationally, according to Ellsworth (2005), requires a “withdrawal from oneself” (31). Unlike Derrida's forgetting, this withdrawl is not an 
alienation or an inauthenticity of the self, but a "condition that frees difference from the determinations of habit, memory, routine and the practices of recognition or identification within which we are caught, opening up other vital possibilities" (31). Visual culture theorist Irit Rogoff (2005) explains this "withdrawal” in other terms, insisting on the potential for emergent collectivities in shared and performed cultural activities. For Rogoff, collectivity is something that takes place when we "look away" from the roles of spectatorship allotted to us in culture, and instead engage with new forms of mutuality that come about through the relations between viewers as participants, rather than those between viewers and objects. In other words, a pedagogy of generosity conceptualized through a "withdrawal" and by "looking away" invokes interconnectivity, embodiment, and motion. Examining the students' artworks beyond the visual, beyond their being simply "objects to look at," pedagogy encourages collectivity through interpersonal, affective relations.

\section{A CONCLUSION - IN THE MAKING}

What might become of pedagogy if we were to consider it from the perspectives of relationality, generosity, and corporeality? In order to establish ways in which we might rethink pedagogy, I argue that we need to investigate the body's participation in learning and knowing. "A body in the process of learning is a body blurred by its own indeterminacy and by its openness to an elsewhere and to an otherwise. This implicates pedagogy in the promise of an indeterminate, unspecifiable future and an unlimited openendedness" (Ellsworth 2005, 122). 
Likewise, there needs to be a shift in the "what" that creates a pedagogical encounter. This means recognizing that the practices that constitute pedagogy are ever changing and evolving, irregular, peculiar, and unexpected. In the context of this research study, pedagogical practices were not limited to the "what" that existed and happened between the students and myself as an artist/researcher/teacher. Rather pedagogy existed in the in-between - by withdrawing and looking away from the normalizing discourses and habits that mark experiences. Similarly, pedagogy did not exist prior to these sites (the teachers, students, the art works) rather pedagogy was created, materialized, and mobilized through participation "in the making." Pedagogy seeps into the cracks inbetween the bodies of the students, in-between their artistic interventions, and in-between the spaces of learning and knowing. According to Grosz (2001) the in-between facilitates and materializes being, identity, and matter. The in-between "is the space in which things are undone, the space to the side and around, which is the space of subversion and fraying, the edges of any identity's limits. In short, it is the space of the bounding and undoing of the identities which constitute it" (Grosz 2001, 93). This thinking of the inbetween of pedagogy presents us with strange and unfamiliar constructs, staging encounters with the unthought, the unknown, and the ambiguous.

It is the event of the unexpected, the being in the making of something different, that Todd (2003) contends makes learning and knowing as a mode of relationality across difference possible. It is the giving over of the self, the affective openness to the other, and the indeterminableness of becoming that is at the heart of a corporeal generosity. 


\section{References}

Ahmed, S. (2000). Strange encounters: Embodied Others in Post-Coloniality. London, : Routledge.

Bagley, C. and Cancienne, M. B. (2001). Educational Research and Intertextual Forms of (Re)presentation: The Case for Dancing the Data. Qualitative Inquiry, 7(2), 221-237.

Bataille, G. (1985). Visions of Excess: Selected Writings 1927-1939 (Allan Stoek1, trans.). University of Minnesota Press.

Bourriaud, N. (2001). Post Production. Paris: Les presses du réel. Bourriaud, N. (2002). Relational Aesthetics. Paris: Les presses du réel.

Brown, B. (2001). Thing Theory. Critical Inquiry, 28(1), 1-22.

Debord, G. (1994). The Society of the Spectacle. New York: Zone Books. de Cosson, A. F. (2003). (Re)searching Sculpted A/r/tography: (Re)learning Subverted-Knowing through Aporetic Praxis. Unpublished doctoral dissertation, The University of British Columbia, Canada.

Deleuze, G. (1993). The Fold: Leibniz and the Baroque. Minneapolis: University of Minnesota Press.

Derrida, J. (1992). Given Time Counterfeit Money. Chicago: University of Chicago Press.

Disprose, R. (2002). Corporeal Generosity: On Giving with Nietzsche, MerleauPonty, and Levinas. Albany: State University of New York.

Eisner, E. (1997). The Promise and Perils of Alternative Forms of Data Representation. Educational Researcher, 26(6), 4-10. 
Ellsworth, E. (2005). Places of Learning: Media, Architecture, Pedagogy. New York: Routledge.

Giroux, H. (2005). Border Crossings: Cultural Workers and the Politics of Education. ( $2^{\text {nd }}$ ed.). New York: Routledge.

Grosz, E. (1994). Volatile Bodies. Bloomington, IN: Indiana University Press.

Grosz, E. (2001). Architecture from the Outside: Essays on Virtual and Real Space. Cambridge, MA: MIT Press.

Irwin, R. L. (2003). Towards an Aesthetic of Unfolding In/sights through Curriculum. Journal of the Canadian Association for Curriculum Studies, 1(2), 63-78. Available at: http://www.csse.ca/CACS/JCACS/PDF\%20Content/07._Irwin.pdf 16pgs. (accessed January 2008).

Irwin, R. L. and de Cosson, A. F. (Eds.). (2004). A/r/tography: Rendering Self through Arts-Based Living Inquiry. Vancouver, BC: Pacific Educational Press.

Levinas, E. (1969). Totality and Infinity: An Essay on Exteriority. Pittsburgh, PA: Duquesne University Press.

Luke, A. (2003). Literacy Education for a New Ethics of Global Community. Language Arts, 81(1), 20-24.

Mauss, M. (1990). The Gift. New York: Routledge.

Merleau-Ponty, M. (1968). The Visible and the Invisible (Alphonso Lingis, trans.). Evanston, IL: Northwestern University Press.

Mullen, C. (2003). Guest Editor's Introduction: A Self-Fashioned Gallery of Aesthetic Practice. Qualitative Inquiry, 9 (2), 165-181.

Nancy, J.L. (2000). Of Being Singular Plural. Stanford, CA: Stanford University Press. 
Pollock, D. (1998). Performative Writing. In Phelan, Peggy \& Lane (Eds.), The Ends of Performance (pp. 73-103). New York: New York University Press.

Rogoff, I. (2000). Terra Infirma: Geography's Visual Culture. London: Routledge.

Rogoff, I. (2005). Looking Away: Participations in Visual Culture. In G. Butt (Ed.), After Criticism: New Responses to Art and Performance (pp. 117-134). Oxford: Blackwell.

Springgay, S. (2002). Arts-Based Educational Research as an Unknowable Text. Alberta Journal of Educational Research, (3). CD Rom.

Springgay, S. (2003). Cloth as Intercorporeality: Touch, Fantasy, and Performance and the Construction of Body Knowledge. International Journal of Education and the Arts, 4(5). Available at: http://ijea.asu.edu/v4n5/.

Springgay, S. (2004). Inside the Visible: Youth Understandings of Body Knowledge through Touch, Unpublished Doctoral Dissertation. Vancouver, BC: The University of British Columbia.

Springgay, S. (2005). Thinking Through Bodies: Bodied Encounters and the Process of Meaning Making in an Email Generated Art Project. Studies in Art Education, 47(1), 34-50.

Springgay, S, Irwin, R. L., and Kind, S. (2005). A/r/tography as Living Inquiry through Art and Text. Qualitative Inquiry, 11(6), 897-912. Todd, S. (2003). Levinas, Psychoanalysis, and Ethical Possibilities in Education. New York: State University of New York Press. 


\section{Notes}

${ }^{1}$ Many contemporary international and Canadian artists create art as a means of social exchange and as circulation. Their works are in part informed by the Situationists International, which emerged as a group in 1957 in France and Germany. Among those most influential in the group was Guy Debord whose book Society of the Spectacle was published in 1967; English translation in 1994. For further readings on contemporary art see Nicolas Bourriaud Relational Aesthetics, 2002; Postproduction, 2001.

${ }^{2} \mathrm{~A} / \mathrm{r} /$ tography is an interdisciplinary methodology that examines the multiple sites of visual and textual interfaces. As a methodology it proposes a complex interweaving of image and word and draws upon a diverse range of theories and practices. For theoretical and conceptual arguments regarding the field in addition to examples of a/r/tographical research see de Cosson, 2003; Irwin, 2003; Irwin \& de Cosson, 2004; Springgay, 2002, 2003, 2004, 2005; Springgay, Irwin, and Kind, 2005.

${ }^{3}$ Students chose their own pseudonyms.

${ }^{4}$ Fifty envelopes were sent. Twenty-five with no stamp. Twenty-five with a stamp. All contained a selfaddressed stamped envelope.

${ }^{5}$ The letter accompanying the items explains that the seeds (which appear to be sunflower seeds) are cupcake seeds.

${ }^{6}$ Folding is where perception is doubled, embodied, and tangled. A fold is both exterior and interior. In a fold inside and outside remain distinct, but not separate, rather they are doubled. Folding may result in additional folds. Thus, the fold appears interconnected, embracing touch and intercorporeality. The condition of the fold is the premise that it is not a void or an absence in the sense of nothing. Rather the fold is being as turned back on itself- touching. Deleuze (1993) translates the fold as sensuous vibrations, a world made up of divergent series, an infinity of pleats and creases. Folding divides endlessly, folds within folds touching one another. "Matter thus offers an infinitely porous, spongy, or cavernous texture without emptiness, caverns endlessly contained in other caverns" (5). Challenging Descartes, Deleuze is mindful of the fold as matter that cannot be divided into separable parts. A fold is not divisible into independent points, but rather any un/folding results in additional folds, it is the movement or operation of one fold to another. "The division of the continuous must not be taken as sand dividing into grains, but as that of a sheet of paper or of a tunic in fold, in such a way that an infinite number of folds can be produced... without the body ever dissolving into point or minima. A fold is always folded within a fold" (6). Perception is not a question then of part to whole but a singular totality "where the totality can be as imperceptible as the parts" (87). Perception is not embodied in perceiving the sum of all parts rather it is distinguished by and within the fold.

${ }^{7}$ Severe acute respiratory syndrome (SARS) was first publicly detected in Canada in the winter of 2003, primarily in the city of Toronto, but Vancouver had a few cases. However, the public media of this disease contorted it to the level of epidemic and a number of people, fearing contamination, chose to mask themselves in public spaces and refused to fly, and even many restaurants and other public spaces were empty. 